\section{Check for updates}

Cite this: J. Mater. Chem. B, 2017, 5, 8125

Received 9th July 2017, Accepted 15th August 2017

DOI: $10.1039 / \mathrm{c} 7 \mathrm{tb} 01854 a$

rsc.li/materials-b

\title{
Antibody-modified hydroxyapatite surfaces for the efficient capture of bladder cancer cells in a patient's urine without recourse to any sample pre-treatment $\uparrow$
}

\author{
Wei Zhang, ${ }^{\text {ab }}$ Kai Zhao, ${ }^{c}$ Craig E. Banks (D)*d and Ying Zhang (D)*a
}

\begin{abstract}
In this study, we describe a sensitive protocol for the detection of bladder cancer cells in a patient's urine without pre-treatment of the urine sample using antibody-modified hydroxyapatite (HAp) micro/ nanostructured surfaces converted from natural seashells under mild biomineralization conditions. The mechanism based on fractal dimension-crystalline phase interactions was utilised for the enhancement of cell capture capabilities that has been verified by application in the determination of 22 urine samples from bladder cancer patients. We have established a facile and economical yet biocompatible and bioactive surface with a topography consisting of micro and nano features that provide useful binding sites for antibodies permitting the rapid identification of cancer cells during urine cytology via fluorescence observation with the naked eye.
\end{abstract}

\section{Introduction}

Bladder cancer is the fourth most frequently diagnosed malignant neoplasm in men and the eighth in women. ${ }^{1}$ Urothelial carcinoma of the bladder (UCB), a common malignancy, accounts for one of the highest management costs per patient of any cancer. ${ }^{2}$ The spread of cancer throughout the body is driven by circulating tumour cells (CTCs) such that new and valuable information about managing cancer, in addition to conventional diagnostic imaging and serum marker detection is made possible, via monitoring CTCs. ${ }^{3}$

In recent years, the detection of bladder cancer by CTCrelated methodologies has been reported, usually dependent upon bio-recognition events between specific cell surface antigens (CSA), such as epithelial cell adhesion molecules (EpCAM) and the human epidermal growth factor receptor 2 (HER2) and the corresponding antibody. ${ }^{4,5}$ However, along with the rare number of CTCs, the sensitivity is always detrimentally influenced by the

\footnotetext{
${ }^{a}$ College of Science, Huazhong Agricultural University, Wuhan 430072, P. R. China. E-mail: zhangying84@mail.hzau.edu.cn

${ }^{b}$ Wuhan Institute of Marine Electric Propulsion, Wuhan 430064, P. R. China

${ }^{c}$ Huazhong University of Science and Technology Tongji Medical College, Wuhan 430030, P. R. China

${ }^{d}$ Faculty of Science and Engineering, Manchester Metropolitan University, Chester Street, Manchester M1 5GD, UK. E-mail: c.banks@mmu.ac.uk

$\dagger$ Electronic supplementary information (ESI) available: Definition of outer and inner surface, results of control groups, disease information to the urine samples, classification of patients' urine samples, three kinds of appearance of urine samples and corresponding typical fluorescence micrographs. See DOI: 10.1039/c7tb01854a
}

complex components of blood. For CTC determination, the most common approach is usually in blood samples, but by its very nature, the matrix is complex resulting in surface adsorption that will influence the results. ${ }^{6}$ Research has been directed to using sandwich assays, such as modifications with silicon nanowire arrays, $\mathrm{TiO}_{2}$ nanowire arrays, fractal gold nanostructures (FAuNSs), conducting polymer based micro/nanorods arrays, conducting polymer nanodots and reduced graphene oxide (rGO) films have all been reported ${ }^{7-13}$ and applied in blood samples.

On the other hand, urine is relatively simpler and determination within this matrix is relatively non-invasive. Cancer cells of clinically relevant bladder and urothelial tumours are routinely shed into urine. The presence of exfoliated tumour cells in urine is the basis of the cytology examination of voided urine, which is currently, the only non-invasive routine standard of care for the surveillance of urothelial cancers. ${ }^{14-16}$ We note that the determination of CTCs in urine is rarely reported. ${ }^{6}$ Attributed to its relatively simple composition, the detection of CTCs in urine is theoretically superior ${ }^{17}$ and its collection more convenient than that of blood. Cancer cells will detach from primary tumour(s) and enter into urine providing a novel route to measure/capture $\mathrm{CTCs}^{18}$ for the early detection of bladder cancer.

However, standard cytology and adjunct molecular tests are always limited by their sensitivity, often due to paucicellularity and the presence of confounding background non-urothelial cells, which have been unable to substitute or reduce the need for cystoscopy. An alternate sensitive, rapid and cost-effective bladder cancer detection and surveillance assay would therefore be beneficial. 


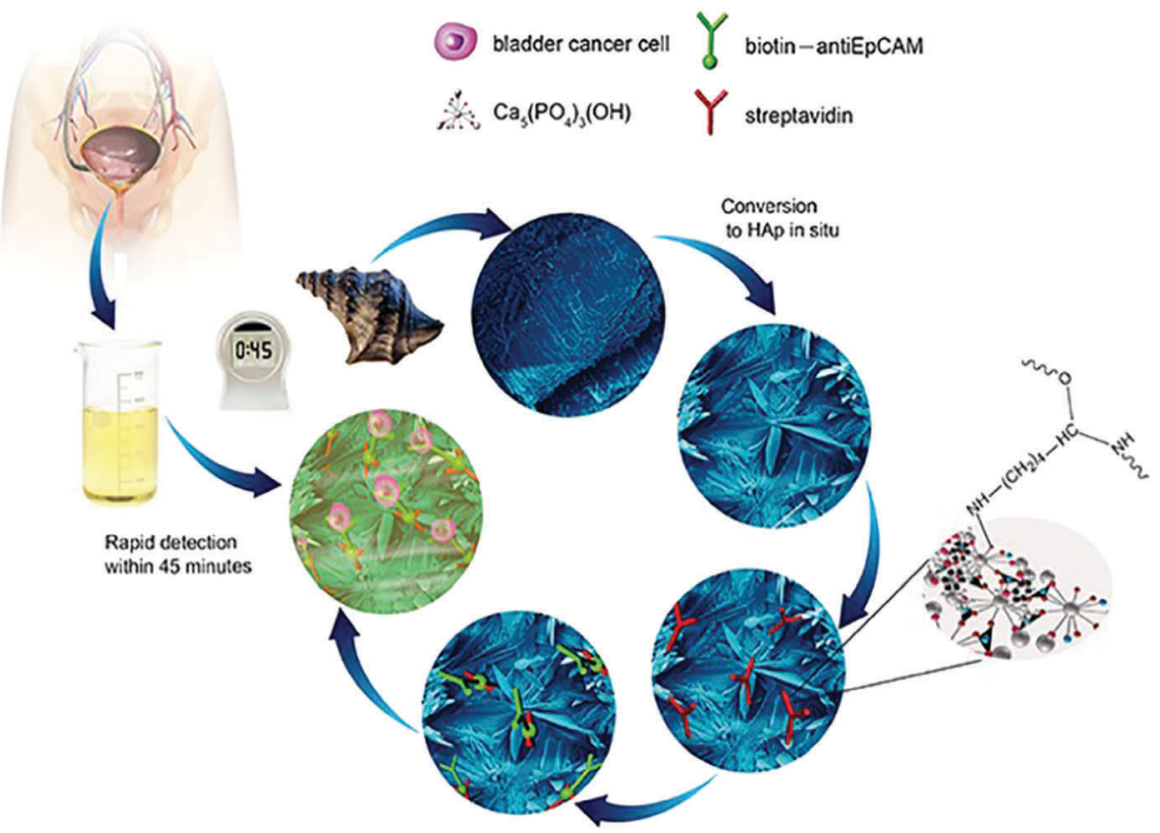

Fig. 1 Schematic diagram summarising the overall concept presented in this paper. First, the natural seashell is converted to HAp in situ under mild biomineralization conditions, which is then functionalized by biotin-antiEpCAM with a streptavidin bridge, accomplished by $\mathrm{OH}-\mathrm{NH}_{2}$ bonding. Subsequently, the functionalized HAp substrate was applied in the rapid detection of bladder cancer cells in patients' urine specimens without any prior sample treatment.

Inspired by nature, inorganic materials fabricated under biomineralized conditions are often equipped with unique morphologies and dedicated microstructures, which exhibit excellent properties and display increasingly important properties in a variety of applications such as tissue engineering, drug delivery and biosensing. Hydroxyapatite $\left(\mathrm{Ca}_{5}\left(\mathrm{PO}_{4}\right)_{3} \mathrm{OH}, \mathrm{HAp}\right)$, a typical example, is known as the main inorganic component in biological hard tissues such as natural bone (95\%) and enamel $(98 \%){ }^{19}$ For this reason, it has been widely applied as a biomedical material in bone implant and other related fields. The physical-chemical and biological-physiological properties of HAp have been shown to be highly dependent upon its morphological properties. ${ }^{20-22}$

In addition to the excellent biocompatibility of biomineralized HAp, the tailored microstructures including morphology and crystalline networks are expected to enhance the local topographic interactions with extracellular extensions. ${ }^{23}$ The HAp platform we present herein, takes advantage of this novel biomaterial for the sensitive capture of bladder cancer cells using functionalized HAp micro/nanostructured agglomerates converted from natural seashells (Charonia tritonis) under mild biomineralization conditions. The HAp platform/surface is then chemically functionalized with EPCAM antibodies by streptavidin (SA) bridging. The amino group of SA interacts with the hydroxyl groups on the HAp surface and by electrostatic attraction of $\mathrm{OH}-\mathrm{NH}_{2}$. The target cancer cells were then captured by subsequent SA and biotinylated EpCAM antibody interactions; see Fig. 1 for graphical representation of the overall process. Unlike other cell capture platforms with artificial micro- or nano-posts, the effective functionalized surfaces proposed here are created by spontaneous formation of micro/nano-agglomerates during the biomineralization process. We have applied this antibody-modified hydroxyapatite platform in the determination of bladder cancer in 22 samples of patient urine without any prior sample treatment, verifying the HAp antibody-modified platform has useful and sensitive detection capabilities for use in urine oncology.

\section{Experimental section}

Fabrication and characterization of the HAp substrate material

In this experiment, $\mathrm{NH}_{4} \mathrm{H}_{2} \mathrm{PO}_{4}$ was purchased from Acros and used without any purification. All solutions and subsequent dilutions were prepared using ultra-pure water $(>18.2 \mathrm{M} \Omega)$ from the Millipore Synergy system (AMETEK, UK). Conch shells (Charonia tritonis) were cut into small pieces, about $10 \mathrm{~mm} \times$ $10 \mathrm{~mm} \times 3 \mathrm{~mm}$, cleaned with deionized water, added into $0.12 \mathrm{~g} \mathrm{~mL}^{-1}$ of a $\mathrm{NH}_{4} \mathrm{H}_{2} \mathrm{PO}_{4}$ solution, and placed in a $40{ }^{\circ} \mathrm{C}$ thermostat for 2 to 21 days. The products were filtered, and alternately washed with ultra-pure water and anhydrous ethanol. After being air-dried at $60{ }^{\circ} \mathrm{C}$ for $12 \mathrm{~h}$, they were characterized using a powder X-Ray Diffraction meter (XRD; D/ruax 2550PC, $\mathrm{CuK} \alpha$ radiation) and a Field Emission Scanning Electron Microscope (FESEM; NOVA NANOSEM 230).

\section{Calculation of fractal dimension}

The fractal dimension, $D_{\mathrm{f}}$ of the biomineralized substrates is calculated by the box-counting methodology which is widely used for fractal dimension determination. The definition of the box-counting dimension is as follows: $D_{\mathrm{B}}=\lim _{\delta \rightarrow 0^{+}} \frac{\log N(\delta)}{-\log \delta}$ where $D_{\mathrm{B}}$ is the box-counting fractal dimension of the structure, 
$\delta$ is the side length of the box, and $N(\delta)$ is the smallest number of boxes of side length $\delta$ required to cover completely the outline of the structure being measured. In practice, a group of sample data $(-\log \delta, \log N(\delta))$ can be obtained and the slope of the line is calculated as the estimation of the box-counting dimension by least-squares linear regression. The $D_{\mathrm{f}}$ of structures in three dimensional space was evaluated as $D_{\mathrm{f}}=D_{\mathrm{B}}+1$. In the current work, MATLAB 2013a was used to calculate the $D_{\mathrm{f}}$ of a biomineralized substrate based on the calculation principle of the box-counting method.

\section{Surface modification of the HAp substrates}

Streptavidin $\left(1 \mathrm{mg} \mathrm{mL}^{-1}\right)$ and biotinylated anti-human EpCAM/ TROP1 antibody (Goat IgG) were obtained from R\&D systems. The substrate was treated with $10 \mu \mathrm{g} \mathrm{mL}{ }^{-1}$ of streptavidin (SA) at $30{ }^{\circ} \mathrm{C}$ for 12 to $8 \mathrm{~h}$, leading to immobilization onto HAp, and then flushed with $1 \times$ PBS to remove excess streptavidin. The substrates can be stored at $4{ }^{\circ} \mathrm{C}$ before use. Prior to cell capture, $50 \mu \mathrm{L}$ biotinylated anti-EpCAM $\left(10 \mu \mathrm{g} \mathrm{mL}^{-1}\right.$ in PBS with $1 \%(\mathrm{w} / \mathrm{v})$ BSA and $0.09 \%(\mathrm{w} / \mathrm{v})$ sodium azide) was dropped onto a piece of HAp substrate and incubated for $1 \mathrm{~h}$ before washing with PBS.

\section{Cell culture}

4-Well Lab-TekTM chamber slides were purchased from Thermo Fisher Scientific. The bladder cancer cell line (EJ) was purchased from American Type Culture Collection (ATCC). Vybrant ${ }^{\mathbb{R}}$ DAPI cell-labelling solution and RPMI-1640 growth medium were obtained from Invitrogen. Multi-Cell ${ }^{\circledR}$ Fetal Bovine Serum (FBS) was obtained from Wisent.

\section{Urine specimen collection}

The fresh morning urines samples were collected from bladder cancer patients by using plastic urine collection tubes and used without any pre-treatment. The samples were placed in an ice-bath for storage. Disease information on the urine samples is summarised and listed in ESI, $\dagger$ Table S1. On the whole, the appearance of the collected urine samples can be typically divided into three classes: clear, cloudy and blood. The total number of urine samples used in this research was 22 , where 7 samples were from Xiangyang (Hubei province), 8 samples from Nanchang (Jiangxi province) and 7 samples from Zhengzhou (Henan province). ESI, $\uparrow$ Table S1 details the urine samples used within this work, namely the gender, age and region of the patient, the appearance of the urine, and the disease type as well as grade/stage of the disease. This work was performed with ethical approval from the University of Wuhan.

\section{Cell capture}

(1) In $1 \times$ PBS solution: the substrates were placed into a sizematched 4-well Lab-TekTM chamber slide and then $1 \mathrm{~mL}$ cell suspensions $\left(10^{5}\right.$ cells per $\left.\mathrm{mL}\right)$ were loaded by a transferpettor. After incubating the device setup for $45 \mathrm{~min}$ at $37^{\circ} \mathrm{C}$ and $5 \%$ $\mathrm{CO}_{2}$, the HAp modified substrate was gently washed with PBS at least 3 times. (2) In patient urine samples: the urine samples were used for the detection of cancer cells by using the

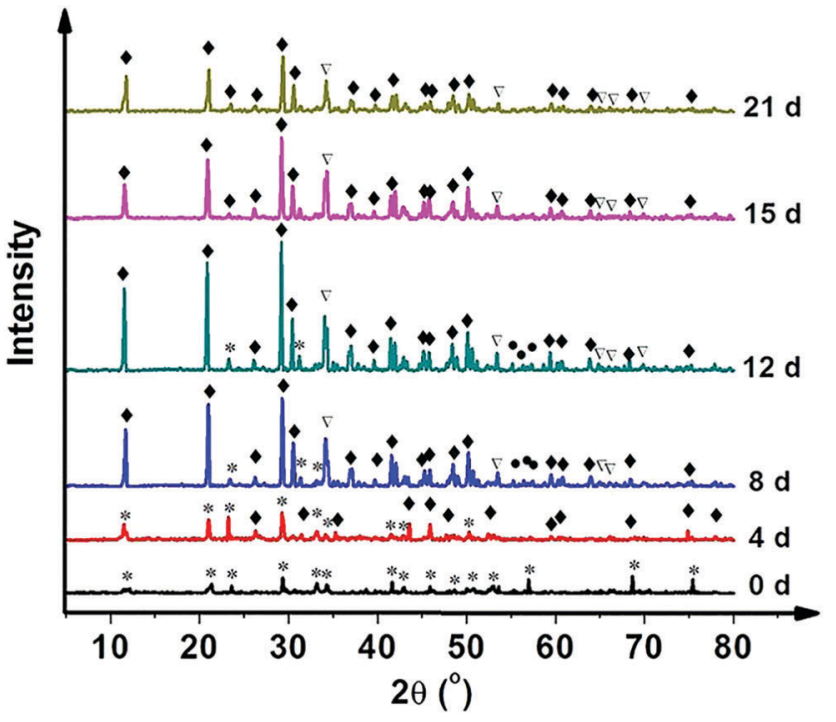

Fig. 2 Crystal phase composition of raw seashell and products converted from seashells over areaction time of 4 to 21 days. Key: ${ }^{\star} \mathrm{CaCO}_{3}, \bullet \mathrm{CaPO}_{3}(\mathrm{OH})$, $\nabla \mathrm{Ca}_{5}\left(\mathrm{PO}_{4}\right)_{3}(\mathrm{OH})$. The XRD patterns clearly confirm that the conversion process is decomposed into two steps: calcite $\rightarrow$ brushite $\rightarrow$ HAp.

as-prepared biomineralized cell-capture antibody-modified HAp platform. The whole experimental process was the same as performed in cell suspension experiments. It is important to note that the freshly collected urine must be used within 4 hours or the cells will disintegrate.

\section{Cell staining and fluorescence observation}

The captured cells on the substrates were fixed with $4 \%$ paraformaldehyde (PFA) in PBS for $20 \mathrm{~min}$. The substrate was subsequently treated with $0.9 \mathrm{~mL}$ of $0.2 \%$ Triton X-100 in PBS for $10 \mathrm{~min}$ to induce cellular permeability and to allow for intracellular staining. To permit the identification of cellular nuclei, the substrate was incubated with a DAPI solution (1 drop of DAPI reagent in $1 \mathrm{~mL}$ of PBS) for $5 \mathrm{~min}$, followed by three PBS washes. Since the biomineralized HAp substrate is not transparent, the substrates were inverted onto a standard cover glass for fluorescence microscope observation. Finally, we imaged and counted cells using a fluorescence microscope (Olympus IX71). Cell counts for dilution experiments were determined by counting three aliquots of cells in succession using a hemacytometer. The cell count accuracy was within $10 \%$.

\section{Control groups}

In order to confirm the indispensable functions of anti-EpCAM and streptavidin in the cell capture process, four control groups of experiments were performed:

(i) Heat inactivation of anti-EpCAM. Thermal inactivation of anti-EpCAM was performed by heating the anti-EpCAM/SA coated substrate to $90{ }^{\circ} \mathrm{C}$ for $10 \mathrm{~min}$, then continuing to carry out the cell capture experiment in the EJ cell suspension;

(ii) Anti-EpCAM denatured by guanidine hydrochloride. The anti-EpCAM was denatured by immersing the biomineralized substrate in $6 \mathrm{~mol} \mathrm{~L}^{-1}$ guanidine hydrochloride for $1 \mathrm{~h}$; 
(iii) Without streptavidin. Anti-EpCAM was directly coated on the biomineralized substrate without streptavidin; (iv) In normal human urine. The urine samples collected from 25 normal people were utilized for the parallel

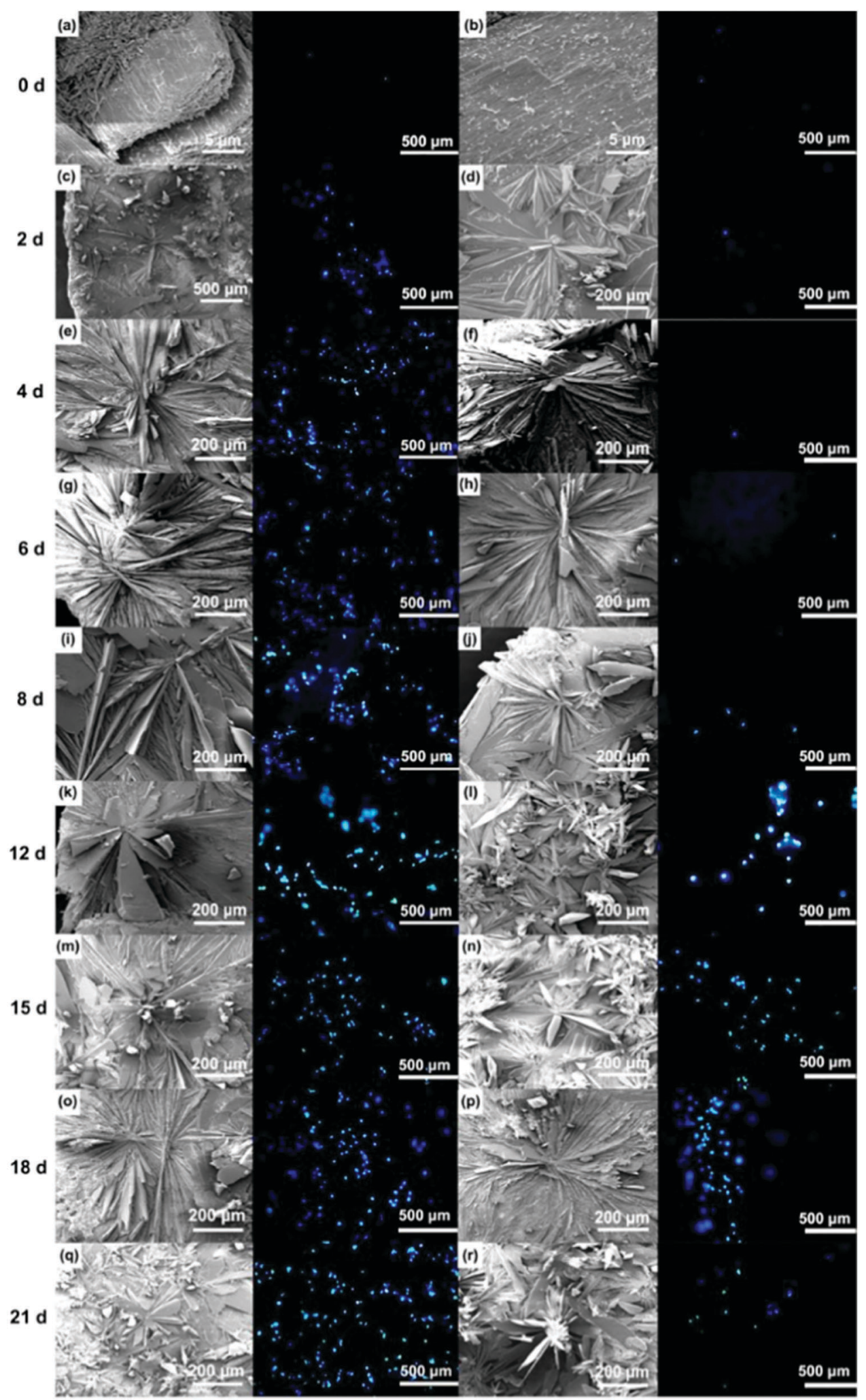

Fig. 3 Comparison of the outer and inner morphologies and cell capture behaviours of the products after conversion for 2 to 21 days. Note: Fig. S1 (ESI $\dagger$ ) defines the outer and inner surfaces of a seashell (conch). 
experiment, aimed at finding out the interference in the urine environment. The whole process kept pace with that for the patient urine.

\section{Results and discussion}

The HAp surfaces/platforms were fabricated as described in the experimental section. The sample phases as a function of synthesis duration time, as shown in Fig. 2, confirm that the conversion process over a time of 4 to 21 days occurs in the following way: a proportion of calcite (the main composition of the seashell) reacts with $\mathrm{NH}_{4} \mathrm{H}_{2} \mathrm{PO}_{4}$ generating $\mathrm{CaPO}_{3}(\mathrm{OH})$ (brushite) as described by the following reaction: $\mathrm{CaCO}_{3}+$ $\mathrm{NH}_{4} \mathrm{H}_{2} \mathrm{PO}_{4} \rightarrow \mathrm{CaPO}_{3}(\mathrm{OH})+\mathrm{NH}_{3}+\mathrm{CO}_{2}+\mathrm{H}_{2} \mathrm{O}$. When the reaction time is extended, the rest of the calcite combines with brushite and forms the HAp crystal: $2 \mathrm{CaCO}_{3}+3 \mathrm{CaPO}_{3}(\mathrm{OH}) \rightarrow$ $\mathrm{Ca}_{5}\left(\mathrm{PO}_{4}\right)_{3} \mathrm{OH}+2 \mathrm{CO}_{2}+\mathrm{H}_{2} \mathrm{O}$.

Scanning electron microscopy images as shown in Fig. 3 illustrate the morphological evolution of the HAp platform over the reaction time of 2 to 21 days' biomineralization. It can be found that both surfaces consist of orientational fibrous texture, but delamination only occurs on the outer surface (Fig. 3a and b). For the 2 to 21 days' samples, both the surfaces are coated with flower-like agglomerates. Interestingly, after the first 2 days, the formed flower-like patterns were not very obvious (Fig. 3c and d). After another 2 days' conversion, these are transformed into 3D agglomerates, comprising micro sheets (Fig. 3e and f). After 6-8 days, the edges became chiselled and diverging (Fig. $3 \mathrm{~g}$ and j). The sheets on the outer surface starts to become obscure again over 12-15 days' conversion (Fig. $3 \mathrm{k}$ and $\mathrm{m}$ ) and the crystals on the inner surface remain flower-like in spite of the decreased size (Fig. 31 and n). The sheets on the outer surface appear to turn to strong and clearly defined structures again after 18-21 days (Fig. 3o and q), while the edges on the inner surface became unclear first and then changed to sharp (Fig. 3p and r). The morphology evolution processes observed herein can be explained by the nucleation-dissolution-recrystallization-self-assembly mechanism. ${ }^{24}$ The corresponding fractal dimensions were calculated by the classical box-counting method (see Experimental section) with the assistance of MATLAB. On the 18th day, the fractal dimensions reached a peak of $1.6 \pm 0.1$ (the outer surface) and $1.8 \pm 0.1$ (the inner surface) $(n>3)$.

To explore the specific cell recognition performance of the HAp biomineralized surfaces, EJ cells (EpCAM positive) were used to measure cells in simulated urine samples in $1 \times$ PBS $\left(10^{5}\right.$ cells per $1 \mathrm{~mL}$ PBS$)$. The functionalized biomineralized substrate and a functionalized raw seashell were then compared to examine how biomineralized agglomerates might increase the capture yield (shown in Fig. 4). The results from spiked cells in buffer solutions clearly show that the biomineralized substrates increase capture efficiency. Furthermore, it can be inferred that the cell capture performance of the inner surface is superior to the outer surface. The raw seashell (conch) structures/surfaces do not have the capability to capture cells but
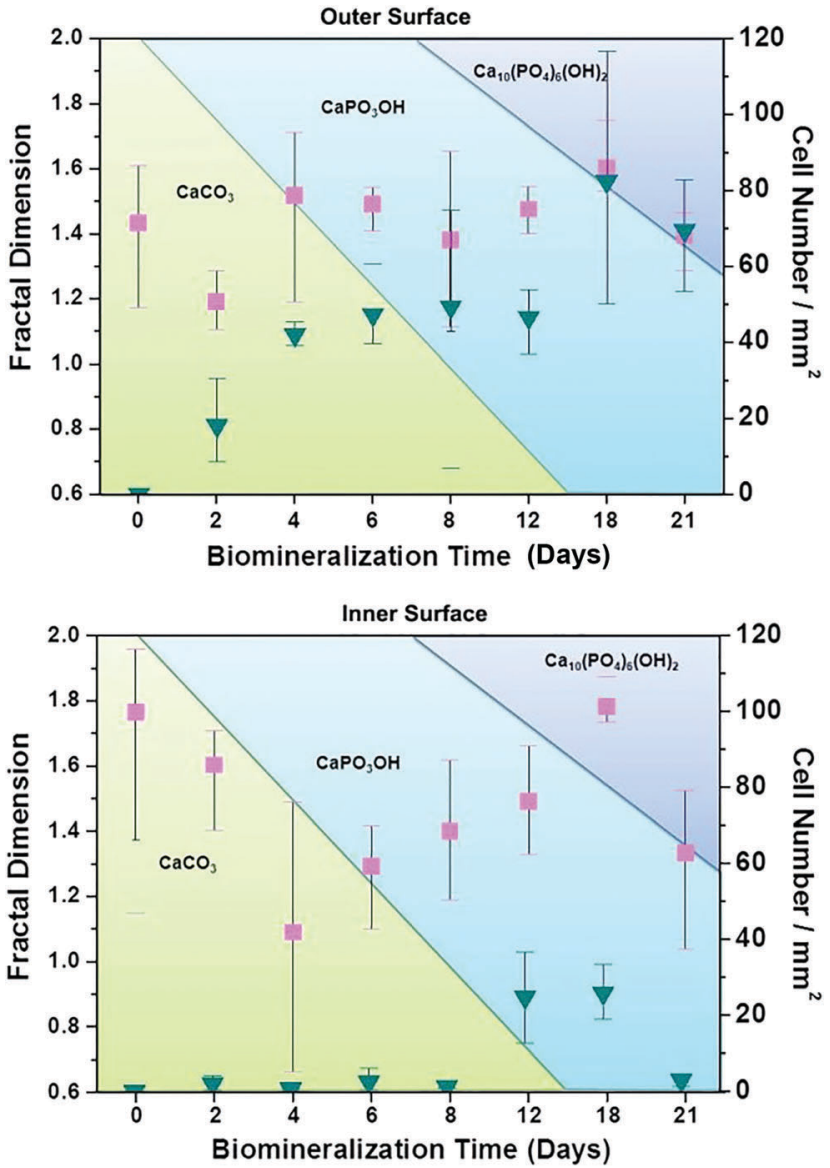

Fig. 4 The relationship between cell-capture performance and the fractal dimension of the as-prepared antibody-modified hydroxyapatite (HAp) surfaces in simulated urine samples on which EJ cells were captured $\left(10^{5} \mathrm{~mL}^{-1}\right)$

when the conversion time is extended from 2 to 18 days, the capture efficiency increases correspondingly due to structural morphological changes. Note that the 18 days' sample has the highest capture efficiency of $70 \% \pm 15 \%$ which likely originates from the crystalline structure/phase composition. However, for the 21 days' sample, the decreased capture efficiency may be attributed to agglomerates forming on the biomineralized surfaces.

To understand the working mechanism of the anti-EpCAMcoated biomineralization interfaces, the relationship between fractal dimension and captured cell number was calculated to reveal the topographic interaction between cancer cells and biomineralized nanostructures, as shown in Fig. 4. It was revealed that the fractal dimension value of the inner surface varies more obviously than that of the outer surface. However, the cell-capture number for the inner surface is much smaller than that for the outer surface. These results indicate that cancer cells prefer to interact with fractal nanostructures with a similar fractal dimension by enhanced topographic interactions. Moreover, as the holding time increases to 18 days, the fractal dimension of both the inner and the outer surface reaches a peak.

According to the XRD characterization results, it is likely that the composition of the crystalline phase plays an important role 
(a)

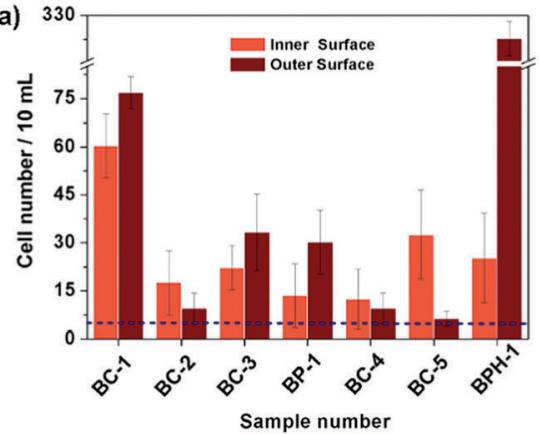

(b)

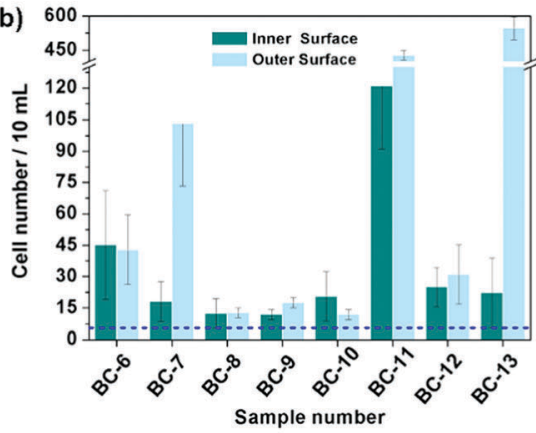

(c)

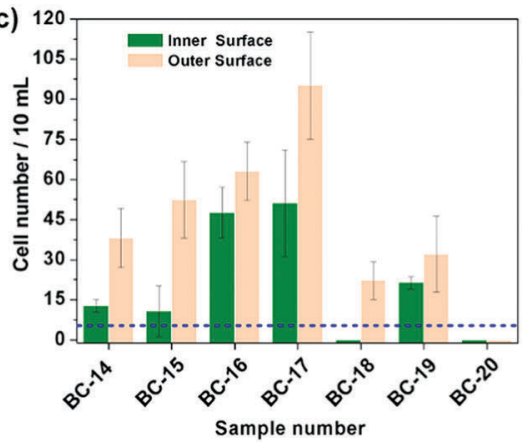

Fig. 5 Cell capture capability of the proposed antibody-modified hydroxyapatite (HAp) surfaces in untreated patients' (a) clear, (b) cloudy and (c) blood urine samples. Dash line: 5 cells per $10 \mathrm{~mL}$ urine. Error bars represent the standard deviation of the average number of cells per $10 \mathrm{~mL}$ samples $(p<0.05)$. Table S1 (ESI $\dagger$ ) provides details of the sample number/patient details.

in enhancing the cell-capture capability over that of the fractal dimension. Furthermore, control groups of experiments confirm that the cell-capture capability of the proposed platform mainly depends on the anti-EpCAM coated on the surface by anti-EpCAM/EpCAM recognition, while streptavidin bridges this antibody and the biomineralized platform (see Fig. S2, ESI $\dagger$ ). Consequently, the cell-capture capability ultimately depends on the composition percentage of HAp within/on the surface of the substrate.

Based on the above results, the 18 days HAp platform was applied to detect cancer cells in human urine. In this work, fresh morning urine samples collected from 22 patients were used for the detection. The classification of patients' urine samples is shown in Fig. S3 (ESI $\left.{ }^{\dagger}\right)$. The determination conditions were the same as in the above tests. In comparison, a normal urine sample was explored as a control (Fig. S2, ESI†). The typical fluorescence micrographs of cell-capture results performed in three kinds of urine samples (clear, cloudy and blood, the appearances are shown in Fig. S4, ESI $\dagger$ ) are displayed in Fig. 5 which clearly confirm good capture capabilities and the promising application potential of our proposed platform. By defining 5 cells per $10 \mathrm{~mL}$ urine samples as a positive result, the statistical data for the determination in the abovementioned three kinds of urine are also summarised. The ratios of positive results to total samples (outer vs. inner) are found to be
9/9 vs. 9/9 (for clear samples), 5/6 vs. 4/6 (for cloudy samples) and 7/7 vs. 7/7 (for blood samples), respectively $(p<0.05)$. This indicates that the cloudy urine environment would negatively influence the detection results due to more interference existing in the sample than in other two samples. Last, Fig. 6 shows the cell capture capability of the proposed HAp substrates/platform in untreated urine samples demonstrating that we cannot find obvious differences in the determination of cancer cells in patients from different regions. For this reason, the proposed cell-capture platform can be considered to be a universal sensing protocol. The ratios of positive results to total samples are 7/7 vs. 7/7 (for samples from Hubei), 8/8 vs. 8/8 (for samples from Jiangxi) and 6/7 vs. 5/7 (for samples from Henan), respectively $(p<0.05)$. In average, the capture efficiency of the proposed HAp platform is $\sim 85 \%$. Although this value is lower than that of the recently reported PPOx platform (up to $100 \%),{ }^{14}$ all the experiments confirm the possibility that the proposed biomineralized platform can be applied as a novel universal strategy for bladder cancer detection in untreated real urine.

On the basis of these measurement results, we classified the diseases that the patients suffered from according to the clinic stages, and the relationship between cell-capture number and the disease is suggested in Fig. 7. The overall tendency of cellcapture number increase with the disease stage is expected, especially for the inner surface of the substrate. However, the
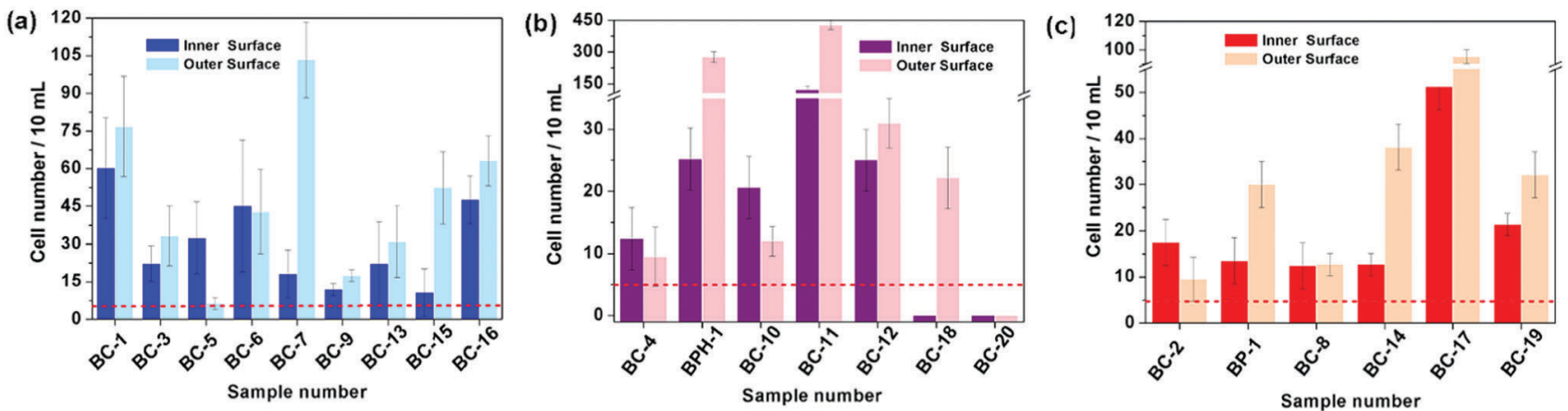

Fig. 6 Cell capture capability of the proposed substrate in untreated urine samples of patients from (a) Hubei, (b) Jiangxi and (c) Henan province. Dashed line: 5 cells per $10 \mathrm{~mL}$ urine. Error bars represent the standard deviation of the average number of cells per $10 \mathrm{~mL}$ samples $(p<0.05)$. Table S1 (ESI $\dagger)$ provides details of the sample number/patient details. 


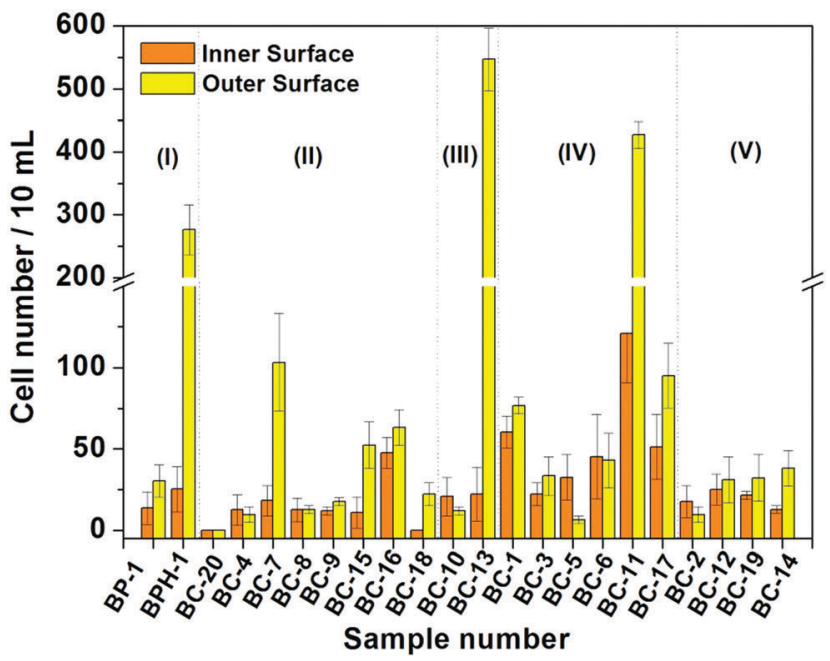

Fig. 7 Cell capture capability of biomineralized platform (18 days) in untreated patients' urine, suffering from (I) benign prostatic hyperplasia and bladder mucosa hyperplasia, (II) low malignant potential papillary urothelial tumors (G1/T1), (III) low-grade papillary urothelial tumors (G3/T1), (IV) high level of non-invasion urothelial carcinoma (G3/T2), and (V) highlevel invasion urothelial carcinoma (G3/T3). Error bars represent the standard deviation of the average number of cells per $10 \mathrm{~mL}$ samples $(p<0.05)$.

unexpected positive results may mainly attribute to the interference by substances in urine such as urinary protein, debris and other background cells, ${ }^{25}$ as well as proliferative cells generated from benign urological lesions ${ }^{26}$ such as bladder polyps and benign prostatic hyperplasia, requiring other techniques (such as the immunohistochemical method) for identification in the future.

\section{Conclusions}

In conclusion, a cell-capture platform based on antibodymodified biomineralized hydroxyapatite substrates from natural seashells has been demonstrated to exhibit efficient and sensitive cell capture applied to the urine of 22 cancer patients without recourse to prior sample pre-treatment. The advantageous performances of using HAp as the basis of the platform is attributed to the enhanced local topographic interactions between the unique crystalline structures and extra cellular extensions, in addition to the excellent biocompatibility. It is inferred that useful sensitivity towards the cancer cells is observed in urine without sample pretreatment due to a combination of urine being a simpler matrix than blood (see introduction of this paper) and reduced fouling properties. Using these antibody-modified HAp substrates we have shown the reliable capture of bladder cancer cells from patients' fresh morning urine samples; it is conceivable that our platform can provide a convenient and cost-efficient alternative for early detection of bladder cancer within the clinic and associated settings.

\section{Conflicts of interest}

There are no conflicts to declare.

\section{Acknowledgements}

The authors gratefully thank the Huazhong University of Science and Technology Tongji Medical College for providing patients' urine samples for this research. This work was financially supported by the National Natural Science Foundation of China (NSFC No. 315008003).

\section{References}

1 N. Wadhwa, S. Jatawa and A. Tiwari, Non-invasive urine based tests for the detection of bladder cancer, J. Clin. Pathol., 2012, 65, 970-975.

2 T. Seisen, T. Jindal, P. Karabon, A. Sood, J. Bellmunt, M. Rouprêt, J. J. Leow, M. W. Vetterlein, M. Sun, S. Alanee, T. K. Choueiri, Q. D. Trinh, M. Menon and F. Abdollah, Efficacy of systemic chemotherapy plus radical nephroureterectomy for metastatic upper tract urothelial carcinoma, Eur. Urol., 2017, 71, 714-718.

3 B. Hong and Y. $\mathrm{Zu}$, Detecting circulating tumor cells: current challenges and new trends, Theranostics, 2013, 3, 377-394.

4 P. Msaouel and M. Koutsilieris, Diagnostic value of circulating tumor cell detection in bladder and urothelial cancer: systematic review and meta-analysis, BMC Cancer, 2011, 11, 336.

5 M. Rink, F. Chun, R. Dahlem, A. Soave, S. Minner, J. Hansen, M. Stoupiec, C. Coith, L. Kluth, S. Ahyai, M. Friedrich, S. Shariat, M. Fisch, K. Pantel and S. Riethdorf, Prognostic role and HER2 expression of circulating tumor cells in peripheral blood of patients prior to radical cystectomy: a prospective study, Eur. Urol., 2012, 61, 810-817.

6 M. Gorin, J. Verdone, E. Toom, T. Bivalacqua, M. Allaf and K. Pienta, Circulating tumour cells as biomarkers of prostate, bladder, and kidney cancer, Nat. Rev. Urol., 2017, 14, 90-97.

7 S. Wang, H. Wang, J. Jiao, K. Chen, G. Owens, K. Kamei, J. Sun, D. Sherman, C. Behrenbruch, H. Wu and H. Tseng, Three-dimensional nanostructured substrates toward efficient capture of circulating tumor cells, Angew. Chem., 2009, 121, 9132-9135.

8 H. Liu, X. Liu, J. Meng, P. Zhang, G. Yang, B. Su, K. Sun, L. Chen, D. Han, S. Wang and L. Jiang, Hydrophobic interaction-mediated capture and release of cancer cells on thermoresponsive nanostructured surfaces, Adv. Mater., 2013, 25, 922-927.

9 Y. Hsiao, S. Luo, S. Hou, B. Zhu, J. Sekine, C. Kuo, D. Chueh, $\mathrm{H}$. Yu, H. Tseng and P. Chen, Bioelectronic interface: Capturing circulating tumor cells onto conducting polymer-based micro/nanorod arrays with chemical and topographical control, Small, 2014, 10, 3012-3017.

10 Y. Li, Q. Lu, H. Liu, J. Wang, P. Zhang, H. Liang, L. Jiang and S. Wang, Antibody-modified reduced graphene oxide films with extreme sensitivity to circulating tumor cells, Adv. Mater., 2015, 27, 6848-6854.

11 J. Sekine, S. Luo, S. Wang, B. Zhu, H. Tseng and H. Yu, Functionalized conducting polymer nanodots for enhanced 
cell capturing: The synergistic effect of capture agents and nanostructures, Adv. Mater., 2011, 23, 4788-4792.

12 P. Zhang, L. Chen, T. Xu, H. Liu, X. Liu, J. Meng, G. Yang, L. Jiang and S. Wang, Programmable fractal nanostructured interfaces for specific recognition and electrochemical release of cancer cells, Adv. Mater., 2013, 25, 3566-3570.

13 N. Zhang, Y. Deng, Q. Tai, B. Cheng, L. Zhao, Q. Shen, R. He, L. Hong, W. Liu, S. Guo, K. Liu, H. Tseng, B. Xiong and X. Zhao, Electrospun $\mathrm{TiO}_{2}$ nanofiber-based cell capture assay for detecting circulating tumor cells from colorectal and gastric cancer patients, Adv. Mater., 2012, 24, 2756-2760.

14 M. Macgregor-Ramiasa, K. McNicholas, K. Ostrikov, J. Li, M. Michael, J. M. Gleadle and K. Vasilev, A platform for selective immuno-capture of cancer cells from urine, Biosens. Bioelectron., 2017, 96, 373-380.

15 K. Kiyoshima, M. Akitake, M. Shiota, A. Takeuchi, R. Takahashi, J. Inokuchi, K. Tatsugami, A. Yokomizo and M. Eton, Prognostic significance of preoperative urine cytology in low-grade non-muscle-invasive bladder cancer, Anticancer Res., 2016, 36, 799-802.

16 J. Zhang, S. Zheng, Z. Fan, Y. Gao, X. Di, D. Wang, Z. Xiao, C. Li, Q. An and S. Cheng, A comparison between microsatellite analysis and cytology of urine for the detection of bladder cancer, Cancer Lett., 2001, 172, 55-58.

17 A. Stolpe, K. Pantel, S. Sleijfer, L. Terstappen and J. Toonder, Circulating tumor cell isolation and diagnostics: toward routine clinical use, Cancer Res., 2011, 71, 5955-5960.

18 T. Szarvas, F. Dorp, S. Ergün and H. Rübben, Matrix metalloproteinases and their clinical relevance in urinary bladder cancer, Nat. Rev. Urol., 2011, 8, 241-254.
19 Q. Liu, S. Huang, J. Matinlinna, Z. Chen and H. Pan, Insight into biological apatite: physiochemical properties and preparation approaches, BioMed Res. Int., 2013, 2013, 929748.

20 M. Salimi and A. Anuar, Characterizations of biocompatible and bioactive hydroxyapatite particles, Procedia Eng., 2013, 53, 192-196.

21 M. Srinivasan, C. Ferraris and T. White, Cadmium and lead ion capture with three dimensionally ordered macroporous hydroxyapatite, Environ. Sci. Technol., 2006, 40, 7054-7059.

22 B. Wang, J. Zhang, Z. Pan, X. Tao and H. Wang, A novel hydrogen peroxide sensor based on the direct electron transfer of horseradish peroxidase immobilized on silicahydroxyapatite hybrid film, Biosens. Bioelectron., 2009, 24, 1141-1145.

23 P. Zhang, L. Chen, T. Xu, H. Liu, X. Liu, J. Meng, G. Yang, S. Wang and L. Jiang, Programmable fractal nanostructured interfaces for specific recognition and electrochemical release of cancer cells, Adv. Mater., 2013, 25, 3566-3570.

24 Y. Zhang, Y. Liu, X. Ji, C. Banks and W. Zhang, Conversion of natural egg-shell to 3D flower-like hydroxyapatite agglomerates for highly sensitive detection of $\mathrm{As}^{3+}$ ions, Mater. Lett., 2012, 78, 120-123.

25 S. Bastacky, S. Ibrahim, S. P. Wilczynski and W. M. Murphy, The accuracy of urinary cytology in daily practice, Cancer Cytopathol., 1999, 87, 118-128.

26 F. Brimo, R. T. Vollmer, B. Case, A. Aprikian, W. Kassouf and M. Auger, Accuracy of urine cytology and the significance of an atypical category, Am. J. Clin. Pathol., 2009, 132, 785-793. 